\title{
Bioética e Biossegurança: Interface necessária no ensino da biotecnologia em programas de pós-graduação no Brasil
}

\author{
Vanessa Trichês Pezente $\mathrm{a}^{*}$ \\ aPrograma de Pós-Graduação em Bioética, Ética Aplicada e Saúde Coletiva pela Universidade Federal do Rio de \\ Janeiro, Rio de Janeiro, Brasil
}

Histórico do Artigo

Recebido em:

21/02/2017

Aceito em: 30/03/2017

\section{Palavras-chave}

Ética

Biossegurança

Educação

Biotecnologia

Keywords

Ethics

Biosafety

Education

Biotechnology

\begin{abstract}
RESUMO
A biotecnologia pode desempenhar tanto um papel positivo quanto negativo, dependendo da forma como for utilizada. Nos últimos anos, com o impacto causado pelos intensos avanços biotecnológicos, a educação científica passou a ser debatida e grades curriculares reformuladas. Neste contexto, a educação em biossegurança e bioética torna-se importante, uma vez que ambos saberes atuam (de forma distinta, mas não separáveis) na prevenção e normatização de ações e produtos resultantes da ação e técnicas biotecnológicas. Este trabalho demonstrou tanto a importância da educação articulada desses dois campos de conhecimento na formação de profissionais cientificamente responsáveis e capacitados para discutir eticamente as questões inerentes à biotecnologia, bem como a prevalência dessa articulação nos cursos de pósgraduação em Biotecnologias no Brasil.
\end{abstract}

Bioethics and Biosafety: Interface needed in the teaching biotechnology in the post-degree courses in Brazil.

\begin{abstract}
Biotechnology can play both positive and negative role depending on the how it is used. In recent years, with the impact of strong advances of the biotechnology, scientific education began to be debated and the curriculum guides needed to be redefined. In this context, the biosafety and bioethics education becomes important as both areas walk together (in a distinct but not disconnected way) in the prevention and standardization of actions and products, resulting from actions and biotechnological techniques. This work demonstrated both the importance of the articulated education of these two fields of knowledge to have professionals who are scientifically responsible and able to discuss ethically the issues inherent to biotechnology, as well as the prevalence of this articulation in the post-degree courses in Biotechnology in Brazil.
\end{abstract}

\section{Introdução}

Diante dos progressivos avanços tecnológicos e científicos presenciados frequentemente, a educação global tem sido revista e reformulada. Notícias relacionadas a novas descobertas científicas e a utilização de novos métodos tecnológicos são veiculadas e, consequentemente, assistidas diariamente (1). Porém, sabe-se que, mesmo sendo importantes tais avanços, principalmente para a saúde, desencadeiam uma série de questionamentos éticos, sociais e legais.

Neste sentido, entende-se que o rápido desenvolvimento tecnológico e científico pode possibilitar tanto a melhoria das condições humanas, como a sua piora, se utilizada de forma inadequada (2). Esses avanços e aplicação de tecnologia em processos biológicos são chamados de biotecnologia. Os recentes avanços da biotecnologia permitiram que novas metodologias fossem desenvolvidas com inúmeros e benéficos resultados no tratamento de diversas patologias que podem afligir o ser humano. Apesar dos proveitosos resultados, tais inovações poderão ter utilizações bélicas (armas biológicas)

\footnotetext{
* Autor correspondente: vanessatp@ outlook.com (V. T. Pezente)
} 
uma vez que seus limites são ainda muito imprecisos (3).

Em 2005, em razão do grande avanço biotecnológico, foi criada a Lei de Biossegurança 11.105/2005 - que estabelece normas de segurança e mecanismos de fiscalização sobre todas as pesquisas que envolvam material biológico. As diretrizes da referida lei apontam para o estímulo ao avanço científico, à proteção à vida e à saúde humana, à animal e à vegetal e à observância do princípio da precaução para a proteção do meio ambiente (4).

Segundo Garrafa (2015), frente aos avanços biotecnológicos, 'o limite não é mais técnico, e, sim, ético'. A questão que se coloca não é mais "não vou fazer porque não posso", mas, sim, "não vou fazer porque não devo fazer". E esse limite ético é dado pela ética aplicada, nesse caso, a Bioética (5). A bioética refere-se ao ramo da ética que enfoca questões referentes à vida humana e, portanto, à saúde. É um estudo sistemático da dimensão moral das ciências da vida e dos cuidados à saúde que busca entender o significado e o alcance das novas descobertas criando regras que possibilitem o melhor uso dessas novas tecnologias sem prejuízos ao ser humano (6).

Bioética e Biossegurança podem ser entendidas, em sentido amplo, como ferramentas teóricas e práticas pertinentes que estudam, avaliam, normatizam e controlam as ações, os produtos e os dispositivos resultantes da competência biotecnocientífica aplicada para transformar sistemas vivos (7).

Sabendo que o progresso da ciência é, de fato, bem mais veloz do que as reflexões sobre as suas repercussões na biosfera e na vida humana, o que torna mais angustiante e premente a discussão acerca dos limites da sua intervenção sobre a vida humana, animal e ambiental (2). Assim, parece legítimo estabelecer uma interface entre esses dois tipos de saber (disciplinas), Biossegurança e Bioética, visto que demonstram compartilhar o mesmo controle e preocupação normativa nas pesquisas biotecnológicas atuais (7).

Diante desses preceitos, é inegável e imprescindível que haja mais discussão sobre as questões morais envolvidas nas pesquisas, bem como a necessidade de articular a Bioética com a Biossegurança (dois tipos de saber distintos, mas não separáveis), no ensino das biotecnologias.

\section{Metodologia}

Para demonstrar a importância dessa articulação entre bioética e biossegurança, realizou-se uma revisão bibliográfica narrativa, que consiste, basicamente, na análise da literatura publicada em livros, artigos indexados e periódicos; na interpretação e análise crítica pessoal. A escolha por este método deve-se ao fato de que, dentre os métodos de revisão, a revisão narrativa possui caráter amplo e abordagem qualitativa, proporcionando um conhecimento mais abrangente (8). Posteriormente, foi realizado um levantamento dos programas de pós-graduação em Biotecnologia ofertados no Brasil e verificada a grade curricular dos mesmos.

As pesquisas foram realizadas nas bases de dados: Scielo, Scopus, Medline/PubMed, Web of Science - Principal Coleção TM , Portal Capes, utilizando os seguintes termos que também representam o vocabulário controlado Mesh/Decs (bioethic, ethic, biosafety, biotechnology, education, bioética, ética, biossegurança, biotecnologia e educação) e em literaturas impressas. Também foram realizadas buscas nos sites dos programas de pós-graduação em Biotecnologia ofertados no Brasil.

\section{Desenvolvimento}

\section{BIOTECNOLOGIA}


A biotecnologia é um campo de saber multidisciplinar ligado a pesquisas biotecnocientíficas, cujo objetivo principal é desenvolver bioprocessos e bioprodutos por meio do uso de materiais biológicos.

A Convenção sobre Diversidade Biológica realizada pela ONU (Organização das Nações Unidas) (9) e publicada em 1992 define biotecnologia como:

Biotecnologia significa qualquer aplicação tecnológica que utilize sistemas biológicos, organismos vivos, ou seus derivados, para fabricar ou modificar produtos ou processos para utilização específica

De forma simples, podemos definir biotecnologia como um campo de conhecimento multidisciplinar que utiliza agentes biológicos para criar produtos úteis ou resolver problemas presentes, incidindo em diversos setores produtivos da sociedade (indústria, energia, meio ambiente, biodiversidade, agricultura, pecuária, alimentos e saúde) estando presente no nosso cotidiano (10).

No entanto, apesar da biotecnologia estar presente no nosso dia a dia e as novas pesquisas apresentarem-se de forma promissora e benéfica, ainda é um campo que suscita opiniões diversas. Segundo Fukuyama, a biotecnologia apresenta uma ameaça sutil e de difícil consenso em qualquer situação em que esteja envolvida (11).

Diante desse contexto, o papel da educação em bioética e biossegurança torna-se fundamental, já que fornece um marco de referência entre as promessas e limites presentes nessa era biotecnológica.

\section{EDUCAÇÃO EM BIOSSEGURANÇA}

A biossegurança, prática cada vez mais presente no cotidiano do profissional de saúde, compreende um campo de conhecimento e um conjunto de práticas e ações técnicas, com preocupações sociais e ambientais, destinados a conhecer e controlar os riscos que o trabalho pode oferecer ao ambiente, à vida humana e à animal (12).

Apresenta como fundamento básico estudar, entender e tomar medidas para prevenir, minimizar ou eliminar os riscos inerentes às atividades da pesquisa, produção, ensino e desenvolvimento tecnológico e proteger a saúde humana, animal e ambiental ou a qualidade dos trabalhos desenvolvidos (13). Também pode ser entendida como um novo tipo de saber que se ocupa dos artefatos (produtos residuais) das biotecnologias, analisando e avaliando seus procedimentos e produtos do ponto de vista de sua segurança, assim necessária para uma política de segurança legítima e eficaz (7).

O termo biosafety, do qual deriva o termo biossegurança, surge depois da Segunda Guerra Mundial, no âmbito do Center of Disease Control (CDC) de Atlanta, com a preocupação de detectar, avaliar e gerir os chamados biorriscos (biohazards), na época definidos como perigos biológicos engendrados diretamente pela natureza ou atividade humana (7).

A biossegurança possui duas vertentes: legal e prática. A vertente legal, regida pela Lei de Biossegurança $n^{\circ} 11.105 / 2005$, que trata das questões envolvendo a manipulação de DNA (Ácido desoxirribonucleico) e a prática, que é empregada nas instituições de saúde que envolvem riscos presentes nesses ambientes (agentes químicos, físicos, biológicos, ergonômicos e psicossociais). No entanto, a biossegurança não se resume apenas a normas de prevenção e controle; sua dimensão científica necessita uma formação educacional adequada para a compreensão dos seus principais objetivos (14).

$\mathrm{Na}$ área da saúde, é possível observar um enorme número de casos que apresentam riscos ocupacionais, cujos profissionais se veem diariamente frente a situações de riscos, especialmente na área biomédica. A biossegurança é, portanto, tema de extrema 
relevância no dia a dia e necessita estar presente ao longo do processo de formação de profissionais nos cursos técnicos. Mastroeni firma que a educação é seguramente a única forma de modificarmos a cultura do fazer 'fácil' pelo fazer 'correto' (15).

Entretanto, é possível observar que a educação em biossegurança no Brasil, apesar de sua importância, ainda não está amplamente inserida nas diretrizes curriculares. Sabe-se que essa deficiência na formação profissional, em virtude do descompasso entre a teoria e a prática, principalmente nos cursos de saúde, é um importante obstáculo no processo educativo (16).

Nesse contexto, é de fundamental importância ampliar a inserção desse campo de conhecimento nas grades curriculares, visando promover ações efetivas de proteção, tendo, assim, a biossegurança respaldada pelo senso de responsabilidade como característica individual e não como uma prática imposta (17).

\section{EDUCAÇÃO EM ÉTICA/BIOÉTICA}

Ética é um termo genérico designado para várias formas de se entender e analisar a vida moral. A ética pode ter abordagem normativa (apresentam padrões de ações boas ou más), descritiva (relatam aquilo em que as pessoas acreditam e como elas agem) ou, ainda, analítica ( analisam os conceitos e os métodos da ética (18).

A ética apresenta como objetivo principal a delimitação de um conjunto de princípios morais que sustentem boas razões para que seja aceito e tenha o comprometimento de alto padrão ético de todos os profissionais envolvidos (19).

Este pensamento em relação a valores foi tornando-se cada vez mais complexo, e, na segunda metade do século XX, a Bioética surgiu para lançar luz a esses pensamentos, com o intuito de lidar com uma crise de valores instalada, advinda das transformações sociais profundas ocorridas (20).

Neste sentido, a bioética parte dos saberes da própria ética filosófica, como uma espécie de ética aplicada. Sua abrangência foi sendo ampliada à medida que os seus problemas relacionados ao desenvolvimento tecnológico e biotecnológico, razão pela qual ela se apresenta como um espaço de reflexão e de ação interdisciplinar que envolve obrigatoriamente a noção de complexidade (21). Van Rensselaer Potter, em resposta ao crescimento exponencial do conhecimento científico e ao atraso da reflexão necessária e primordial a sua utilização, definiu-a como uma ciência da sobrevivência que se baseia na aliança no saber biológico (bio) com os valores humanos (ética) - bioética (22).

Os objetivos da bioética nascem diferentes dos da ética profissional, pois não têm base na proibição ou na negação. Ela atua com o intuito de legitimar ações e situações, atuando positivamente, sob a essência da liberdade, porém com compromisso e responsabilidade, contextualizando cada situação de conflito, dentro de seus aspectos sociais, culturais, econômicos e biológicos (23).

A bioética pode ser considerada como um novo âmbito da ética, que se ocupa da moralidade dos atos biotecnocientíficos. Pode ser concebida de várias maneiras de acordo com as características do seu objeto, dos métodos adotados ou contexto em que queira inscrever suas atividades (ética da vida; ética da sacralidade da vida; implicações morais da práxis humana etc). Apesar das suas diferenças, todas as definições de ética possuem dois elementos em comum: moralidade (referida ao agente moral ou ao ato oriundo desse agente) e referência à vida (24-26).

Podemos entender a bioética com um significado mais abrangente, como sendo "a ética da vida", ou com significado circunscrito, como apontado por Schramm, entendida de forma literal como "a ética aplicada ao bios, à vida humana naquilo que ela teria de específica: a vida moral, isto é, a competência em distinguir entre o bem e o mal..." 
(27). Em resumo, pode-se definir a bioética como prática e discurso que têm por objetivo esclarecer ou resolver as questões éticas suscitadas pelo desenvolvimento tecnocientífico no campo da saúde e da vida humana (22).

A proposta da bioética é inerentemente complexa porque trata de questões éticas plasmadas em um mundo plural e culturalmente diversificado, por isso ela é composta pela confluência de numerosas disciplinas, tais como: filosofia (ética), medicina, biologia, sociologia, antropologia, economia, direito etc, além de ser um campo que está presente em temáticas que envolvem a sociedade e o meio ambiente. Possui uma abordagem interdisciplinar que permite analisar as situações e problemas éticos de forma abrangente e individual, verificando todas as perspectivas envolvidas e todas as linguagens de compreensão de cada disciplina (28).

Durante a $32^{\mathrm{a}}$ Conferência Geral da UNESCO em 2003, foi identificada a necessidade de iniciar e apoiar o ensino em ética, visando habilitar os estudantes a reconhecer a analisar questões éticas, assim como capacitá-los a agir eticamente mediante as situações surgidas. Recomendou-se, ainda, que o ensino da ética seja em vários níveis, desde a graduação até a pós-graduaçao. Diante disso, torna-se evidente a necessidade da inserção deste saber nas grades curriculares de formação profissional das diversas áreas afins $(29,19)$.

\section{INTERFACE DA BIOÉTICA E BIOSSEGURANÇA}

O desenvolvimento da biotecnologia demonstra uma série de preocupações tanto para cientistas quanto para a sociedade em geral. Dentre essas preocupações, destaca-se a necessidade de educar cientificamente e moralmente os pesquisadores envolvidos com bioprocessos, visando formar profissionais especializados, capacitados e responsáveis, tanto pelas descobertas quanto pelos artefatos gerados em suas pesquisas científicas. (14).

Entendendo, neste sentido, a educação como aquela que fornece ao homem a construção de sua identidade própria, a interação com outras pessoas e uma sociedade atenta a diferenças e semelhanças, responsável por um humano capacitado para superar as necessidades que the forem impostas. E se pensarmos nela como um processo constante, ela poderá extrair o máximo do potencial do sujeito que o capacitará à aquisição de habilidades, não se resumindo em transferência de conhecimento, mas, sim, em possibilidades para construção e produção de conhecimento individual (30).

Machado (31) ressalta a importância de uma educação contextualizada com a atualidade, uma vez que as novas tecnologias exigem profissionais capacitados, especializados e responsáveis. Neste sentido, a bioética, em conjunto com a biossegurança, pode ser percebida como campo de saber científico, que visa refletir, entender e acompanhar o progresso, sem impedir os avanços científicos (3).

A bioética e a biossegurança aproximam-se no que se refere à ponderação entre a probabilidade de riscos e benefícios esperados das novas biotecnologias. Entretanto, apesar dessa proximidade, são âmbitos disciplinares distintos. Enquanto a bioética preocupa-se com a moralidade dos atos biotecnocientíficos, a biossegurança ocupa-se com os riscos biológicos envolvidos no uso das biotecnologias no ambiente de trabalho e na sociedade em geral, lançando mão de medidas técnicas e legais. Assim, bioética e biossegurança podem ser entendidas, em sentido amplo, como caixa de ferramentas teóricas e práticas pertinentes que estudam, avaliam, normatizam e controlam as ações, os produtos e os dispositivos resultantes da competência biotecnocientífica aplicada para transformar seres e sistemas vivos (7).

Em termos lógicos, a relação estabelecida entre tais saberes é de conjunção-disjunção 
não excludente, pois se preocupam com problemas reais comuns e com consequências em termos de riscos e danos, entretanto, com olhares diferentes - representados pelo ponto de vista da bioética e da biossegurança. Mas essa conjunção-disjunção é possível através de um método que, segundo Morin, é capaz de distinguir sem separar e juntar sem confundir que permite tratar a complexidade destes saberes (32). A interface bioética-biossegurança pode ser vista como pertencente ao paradigma da complexidade (quadro epistemológico, teórico e conceitual que serve para estudo dos fenômenos humanos e sociais), considerando-os como saberes normativos parcialmente autônomos (33).

Essa interface pode ser visualizada quando, por exemplo, ambos saberes se referem a alguma forma de controle das práticas de biotecnologias, devido a uma real ou suposta periculosidade, presente ou futura de seus processos e produtos. Se, por um lado, a biossegurança preocupa-se com a legitimidade, a bioética preocupa-se com a justificação normativa (34).

De maneira sintética, é possível afirmar que já existe uma interface entre bioética e biossegurança, uma vez que ambas preocupam-se com práticas comuns, como proteger populações humanas em situação de risco através da adoção de medidas necessárias para atingir o objetivo comum, proteger quem precisa. Com relação à biotecnologia, tanto a biossegurança quanto a bioética se preocupam com seus possíveis desdobramentos, justificando a interface dos saberes em suas abordagens respectivas da periculosidade dos bioprocessos e bioprodutos. Pode-se afirmar, assim, que a bioética analisa a moralidade das biotecnologias, justificando-as ou não, e a biossegurança calcula, pondera e gere os riscos inerentes das pesquisas (7).

A necessidade de considerar uma interface entre bioética e biossegurança se torna cada vez mais evidente e necessária nos dias de hoje (5). Sabe-se que a biotecnologia não retrocede em seus avanços científicos e que muitos cientistas e pesquisadores agregaram a razão à ciência, deixando a ética de lado (7). Diante deste preceito, biossegurança atuaria na regulação das pesquisas, de acordo com as leis vigentes e a bioética na legitimação (justificação) ou não das mesmas, perante a sociedade. Ambos saberes colaborariam para construir pontos de convergência acerca de como encarar, de forma racional e não só legal, até onde é permitido avançar as pesquisas biotecnológicas, minimizando os possíveis riscos inerentes a era biotecnológica.

\section{BIOÉTICA E BIOSSEGURANÇA NOS PROGRAMAS DE PÓS-GRADUAÇÃo EM BIOTECNOLOGIA NO BRASIL}

O acontecimento base para a biotecnologia moderna ocorreu em 1953, quando a estrutura do DNA foi identificada por Watson e Crick e, 20 anos depois, este processo foi incrementado com o desenvolvimento da base de recombinação de segmentos de DNA, feito por Stanley Cohen e Herbert Boyer. Este foi um marco definitivo entre a biotecnologia tradicional e a moderna. $\mathrm{O}$ terceiro momento de salto tecnológico nessa área ocorreu em 1980, com o escalonamento do sequenciamento genético, tendo o custo desse processo reduzido e então difundido globalmente, permitindo, assim, que países em desenvolvimento - como Brasil, Índia, Coréia, China e outros - pudessem aperfeiçoar suas capacidades científicas e tecnológicas (35).

Atualmente, o país que concentra o maior número de empresas em biotecnologia é a Índia. Na sequência do ranking, situam-se a Coreia do Sul, o Canadá, a Alemanha e a China. O Brasil aparece nesse ranking em $11^{\mathrm{o}}$ lugar, criando novos empregos, desenvolvimento de vacinas e biogenéricos (36).

O Brasil começou tardiamente seu processo científico-tecnológico, tendo suas 
primeiras universidades fundadas apenas a partir do século $\mathrm{XX}$, enquanto universidades europeias e americanas datam, respectivamente, dos séculos XI e XVII. Nossos institutos de pesquisa e empresas tecnológicas datam do século $\mathrm{XX}$ e nossas financiadoras de pesquisa só foram criadas a partir da década de 1950. A formação de profissionais capacitados para Ciência e Tecnologia (C\&T) iniciou-se nos anos 1950, sendo os últimos 20 anos marcados pelo crescente investimento em projetos de diferentes áreas afins, principalmente nas áreas da saúde e agronegócios (37).

Embora tardio, no Brasil a oferta de cursos na área Biotecnológica tem aumentado significativamente na última década, apresentando uma forte capacitação em material humano, que atua principalmente em pesquisa básica, apresentando e provendo boa formação universitária. O Brasil tem uma liderança em Pesquisa e Desenvolvimento (P\&D) entre os países em desenvolvimento, apresentando excelentes laboratórios em âmbito federal e estadual, que atuam de forma inteligente, formando redes de pesquisa (38). Trata-se, portanto, de um campo em progressiva e constante expansão, e que aos poucos vem se reformulando.

As grades curriculares, desde o início, sofreram grandes alterações, dentre elas, a inclusão de disciplinas que visam desenvolver um caráter ético e moral aos pesquisadores, como a bioética e a biossegurança. A bioética insere-se em um contexto amplo, pois surge relacionada com as exigências da sociedade que questionam os próprios limites legais da prática, vinculando-se ao exercício efetivo da própria cidadania (39). Já a biossegurança insere-se como um conjunto de procedimentos que visam controlar e prevenir os riscos à saúde humana, animal e ambiental, advindos das práticas tecnológicas, assegurando um avanço tecnológico seguro e responsável (14).

Segundo a Coordenação de Aperfeiçoamento de Pessoal no Nível Superior (CAPES), em final de 2015, totalizavam-se 58 Programas de Pós-Graduação em Biotecnologia disponibilizados no Brasil. Abaixo, a figura 1 demonstra como estão distribuídos estes cursos (40). 


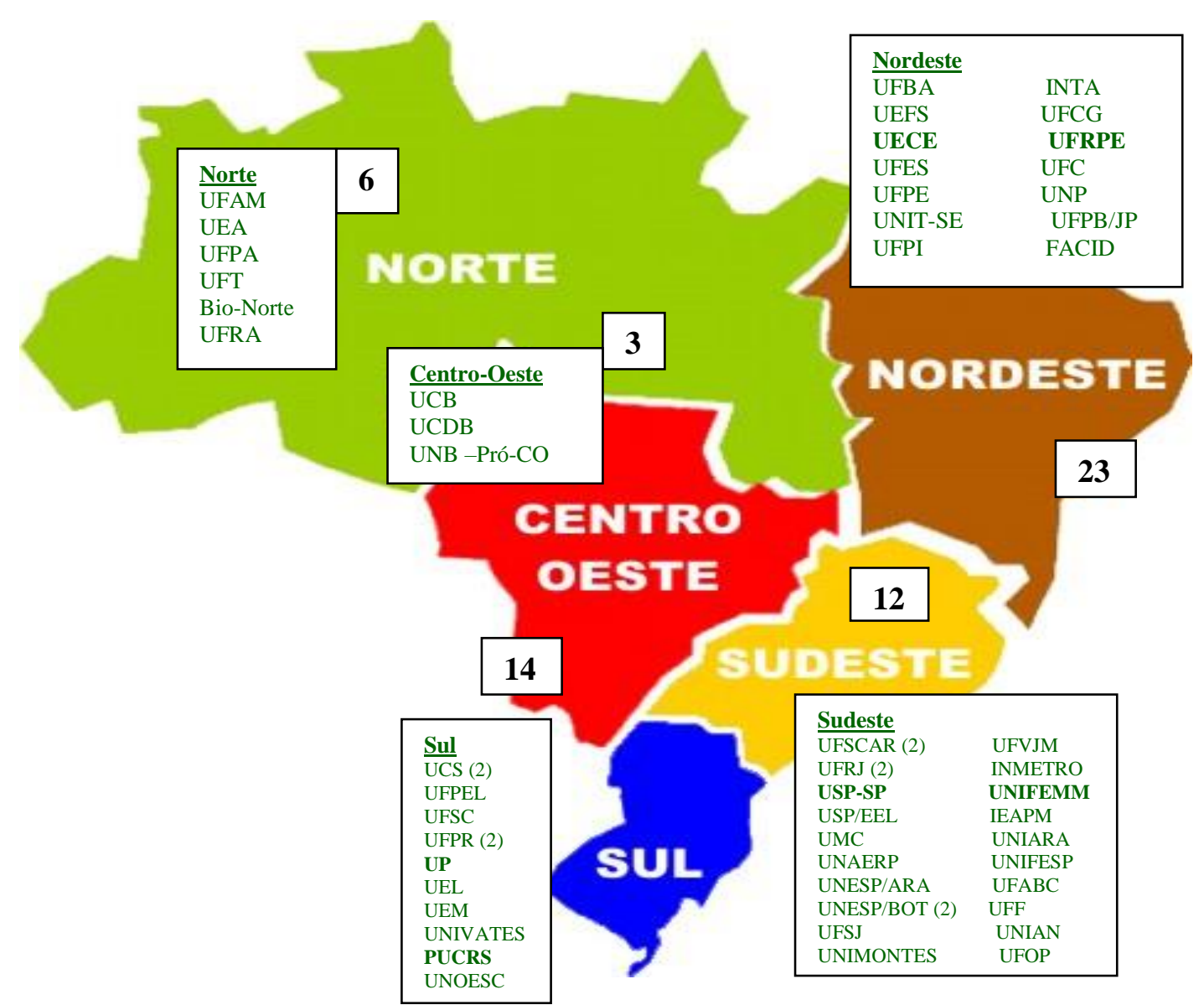

Figura 1. Distribuição Nacional dos programas de Pós-Graduação em Biotecnologia.

Conforme demonstrado na figura acima, é possível observar que a maior concentração de programas de pós-graduação em Biotecnologia, aproximadamente 50\%, encontramse na região sudeste do Brasil. Isto se dá, provavelmente, devido a esta região ter sido a pioneira no apoio sistemático aos procedimentos biotecnológicos modernos e na formação de profissionais capacitados para Ciência e Tecnologia (38).

Estudos relatam que os estados de São Paulo e Minas Gerais criaram projetos, como Projeto Genoma Humano e Science Park respectivamente, antes mesmo de o governo federal reconhecer a importância da área biotecnológica (38).

Ao analisar as grades curriculares disponíveis no site das Instituições ofertantes deste curso, pode-se observar que, como demonstrado na tabela abaixo (Quadro 1), aproximadamente $40 \%$ dos programas já oferecem as disciplinas de bioética e biossegurança de forma articulada, estando estas concentradas, principalmente, na região sudeste.

Quadro 1. Bioética e Biossegurança nos Programas de Pós-Graduação em Biotecnologia no Brasil.

\begin{tabular}{|c|c|c|c|c|c|}
\hline \hline Disciplinas & $\begin{array}{c}\text { Bioétic } \\
\mathbf{a}\end{array}$ & Biossegurança & $\begin{array}{c}\text { Bioética \& } \\
\text { Biossegurança }\end{array}$ & $\begin{array}{c}\text { Não } \\
\text { Aplicável }\end{array}$ & $\begin{array}{c}\text { Grade não } \\
\text { Divulgada }\end{array}$ \\
\hline $\begin{array}{c}\text { Número de } \\
\text { Instituições }\end{array}$ & 04 & 07 & 27 & 15 & 05 \\
\hline \hline
\end{tabular}

Estes dados demonstram, também, que sete instituições oferecem apenas a disciplina de biossegurança, enquanto quatro oferecem somente a disciplina de bioética. 
Analisando o conteúdo programático individual dessas disciplinas, foi possível verificar a inexistência de relação entre ambas, sendo as disciplinas ofertadas com características específicas distintas.

Outro aspecto importante desta tabela é que, dentre as 58 instituições pesquisadas, cinco não disponibilizam a grade curricular nos sites ou email; 15 não ofertam nenhuma das disciplinas citadas e apenas uma oferece ambas as disciplinas de forma distinta e não articulada. Um detalhe que merece destaque é que cerca de $90 \%$ dos programas de pós-graduação oferecem estas disciplinas com caráter eletivo/opcional e não obrigatório, como proposto neste trabalho. Os 10\% restantes que apresentam as disciplinas de forma obrigatória concentram-se, principalmente, na região sudeste.

Os avanços no campo das biotecnologias, principalmente no que se refere ao aperfeiçoamento das técnicas já existentes e, sobretudo, no âmbito mais recente das biotécnicas de manipulação genética, têm gerado profundas discussões de fundo ético, legal e social. Ocorre que a (in)capacidade humana para prever as consequências dos usos dessas tecnologias é o grande desafio para opinar sobre o sim ou o não de determinadas práticas científicas (42).

Como alternativa para solucionar estes embates, a educação em bioética e biossegurança deve acontecer de forma articulada, em conjunto, normatizando e legitimando essas pesquisas científicas, visando prevenir, controlar e minimizar os riscos presentes, permitindo, portanto, que os avanços biotecnológicos aconteçam de forma segura e responsável.

\section{Considerações finais}

Os avanços biotecnológicos presenciados pela humanidade nas últimas décadas têm colocado o ser humano frente a situações até pouco inimagináveis. Com o advento da biotecnologia, novos produtos e processos estão surgindo e, com eles, muitos questionamentos éticos, sociais e legais. Desta forma, entende-se que o limite para as pesquisas não é mais técnico, mas, sim, de natureza ética.

A construção da alteridade biotecnológica passa, necessariamente, pela educação científica. Esta educação deve comprometer-se com a formação de pesquisadores cientificamente esclarecidos e responsáveis e não apenas técnicos. Para tal, este trabalho demonstrou a importância de um ensino articulado entre bioética e biossegurança, visando assegurar que a execução de ações na área biotecnológica seja respaldada na responsabilidade com o outro.

Sabendo que biossegurança e bioética são saberes complexos e necessários não somente para profissionais de biotecnologia, mas também para todos os pesquisadores das diversas áreas, torna-se fundamental seu debate e esclarecimento, a fim de contribuir na proteção da saúde humana, animal e ambiental, sem impedir os avanços tecnológicos, uma vez que a biossegurança irá quantificar e ponderar os riscos e benefícios, enquanto a bioética analisará os argumentos racionais que justificam ou não tais riscos presentes.

Diante desses preceitos, é inegável e imprescindível que haja maiores discussões sobre as questões morais envolvidas nas pesquisas bem como a necessidade de difundir o ensino articulado da bioética com a biossegurança, uma vez que estes dois tipos de saberes, apesar de distintos, não são separáveis no ensino das biotecnologias.

Conflito de interesses: A autora declara não haver conflito de interesses

\section{Referências}


1. Pessini L. Distanásia: até quando prolongar a vida? São Paulo: Editora do Centro Universitário São Camilo/Loyola; 2001.

2. Clotet J. Bioética como Ética Aplicada e Genética. Revista Bioética 2009; 5 (2): 1-9.

3. Galamas F. Avanços da Biotecnologia e Impacto na Biossegurança. In: workshop-Biossegurança, 2012. Disponível em: http://repositorio.insa.pt/bitstream/10400.18/1538/3/Workshop\%20Biosseguran\%C3\%A7a\%20$\% 20$ Situa $\%$ C3\%A7\%C3\%A3o\%20em\%20Portugal.pdf\#page=29

4. Brasil. Lei n. 11.105/05. Regulamenta os incisos II, IV e V do § 1o do art. 225 da Constituição Federal, estabelece normas de segurança e mecanismos de fiscalização de atividades que envolvam organismos geneticamente modificados - OGM e seus derivados, cria o Conselho Nacional de Biossegurança - CNBS, reestrutura a Comissão Técnica Nacional de Biossegurança - CTNBio, dispõe sobre a Política Nacional de Biossegurança - PNB, revoga a Lei no 8.974, de 5 de janeiro de 1995, e a

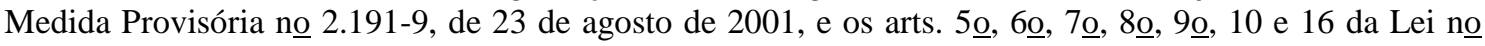
10.814, de 15 de dezembro de 2003, e dá outras providências, (2005).

5. Garrafa V. Bioética e ciência: Até onde avançar sem agredir. Entrevista com Volnei Garrafa. Disponível em: http://www.dhnet.org.br/direitos/direitosglobais/paradigmas_textos/bioetica2.html

6. Dantas I. A era da biotecnologia constituição, bioética e biodireito. Capítulo de livro em preparação sobre BioDireito Constitucional a ser publicado, 2005. Disponível em: http://www.oab.org.br/editora/revista/users/revista/1205505342174218181901.pdf

7. Schramm FR. Bioética 'e/ou'Biossegurança. In: Três Ensaios de Bioética. Rio de Janeiro: FioCruz; 2015. p 119-131.

8. Mendes KD, Silveira RCCP, Galvao CM. Revisão integrativa: método de pesquisa para a incorporação de evidências na saúde e na enfermagem. Texto contexto - enfermagem 2008; 17 (4): 758 764.

9. Brasil. Decreto Legislativo n. 2, de 5 de junho de 1992. Convenção sobre diversidade biológica publicada pelo Ministério do Meio Ambiente. Brasília, (1992).

10. Malajovich MA. Biotecnologia. Rio de Janeiro, Edições da Biblioteca Max Feffer do Instituto de Tecnologia ORT, 2012.

11. Fukuyama F. O nosso futuro pós-humano. Consequências da revolução da bioecnologia. Rio de Janeiro: Rocco, 2003.

12. Almeida AB; Albuquerque MBM. Biossegurança: um enfoque histórico através da história oral. História das Ciências de Saúde - Manguinhos 2000; 7 (1): 171- 183.

13. Teixeira P, Valle S. Biossegurança: uma abordagem multidisciplinar. 2 ed. Rio de Janeiro: FioCruz, 2010 .

14. Costa MAF, Costa MFB. Educação em biossegurança: contribuições pedagógicas para a formação profissional em saúde .Ciênc. saúde coletiva 2010; 15 (1): 1741-1750.

15. Mastroeni, MF. A difícil tarefa de praticar a biossegurança. Ciência e Cultura. 2008; 60 (2): 4-5.

16. Costa MAF, Costa MFB, Murito MMC, Carvalho PR, Pereira MEC. Biossegurança no ensino médio: uma discussão preliminar sobre conteúdos em livros didáticos de ciências e práticas docentes. In: Seminário Nacional de Educação Profissional e Tecnológica 1., 2008, Belo Horizonte. Disponível em: http://www.senept.cefetmg.br/galerias/Arquivos_senept/anais/terca_tema1/TerxaTema1 Artigo3.pdf.

17. Gir E, et al. Biossegurança em DST/AIDS: condicionantes da adesão do trabalhador de enfermagem às precauções. Revista da Escola de Enfermagem da USP 2004; 38 (3): 245-253.

18. Beauchamp TL, Childresss JF. Princípios de Ética Biomédica. $3^{\text {a }}$ ed. São Paulo: Loyola, 2013

19. UNESCO. Report of the Working Groupon the Teaching of Ethics of the World Commission on the Ethics of Scientific Knowledge and Technology (COMEST) Paris 2003. Disponível em: http://unesdoc.unesco.org/images/0013/001345/134552mb.pdf4

20. Ladeira TL. Significados, sentidos e vozes do cuidado integral: aspectos bioéticos na formação do fisioterapeuta. Niterói: Universidade Federal Fluminense; 2014.

21. Goldim JR. Bioética: origens e complexidade. Revista HCPA 2006; 26 (2): 86-92.

22. Durand G. Introdução Geral à Bioética: História, Conceitos e Instrumentos. 5 ed. São Paulo: São Camilo, Edições Loyola, 2014.

23. Garrafa V. Introdução à Bioética. Revista do Hospital Universitário. 2005: 6 (2): 9-13. 


\section{Vittalle - Revista de Ciências da Saúde 29 n. 2 (2017) 85-95}

24. Kottow M. Introducción a La bioética. Santiago: Universitaria, 1995. Avaliable from: http://si.easp.es/eticaysalud/sites/default/files/1\%20INTRODUCCION\%20A\%20LA\%20BIOETICA.pdf.

25. Reich W. Introduction. In: (org.). Encyclopedia of Bioéthics. 2 ed. Nova York: Simon \& Schuster; Macmillan, 1995.

26. Mori M. A Bioética: sua natureza e história. Trad. Fermin Roland Schuramm. Humanidades. v. 9, n. 4, p.332-341, 1994.

27. Schramm FR. A moralidade da Biotecnociência: A Bioética da proteção pode dar conta do impacto real e potencial das biotecnologias sobre a vida e/ou a qualidade de vida das pessoas humanas? In: Bioética: riscos e proteção. Rio de Janeiro: UFRJ/FioCruz, 2009

28. O’Neill O. Autonomy and trust in Bioethics. Cambridge: Cambridge University, 2002.

29. UNESCO. The Activities of UNESCO in the Area of Ethics. Kennedy Institute of Ethics Journal. 2006;16 (4): 333-51.

30. Machado D, Carvalho M, Machado B, Pacheco F. A formação ética do fisioterapeuta. Physical therapist ethical formation. Fisioterapia em movimento. 2007; 20 (3):101-5.

31. Machado LRS. Educação e os desafios da novas tecnologias. In: Ferreti CJ, organizador. Novas tecnologias, trabalho e educação: um debate multidisciplinar. Petrópolis: Vozes, 1998.

32. Morin E. Introduction à la Pensée Complexe. Paris: ESF, 1990.

33. Mucchielli A. Complexité [paradigme de la]. In: Mucchielli A. (Dir.). Dictionnaire des Méthodes Qualitatives em Sciences Humaines. 3a ed. Paris: Armand Colin, 2011.

34. Schramm FR. Bioética, biossegurança e a questão da interface no controle das práticas da biotecnociência: uma introdução. Revista Redbioética/Unesco, 2010. 1(2): 99-110.

35. Fonseca MGD. Identificando tendências de mercado e oportunidades em biotecnologia. In: UZIEL, D. (org.). Biotecnologia no Brasil: financiamento, parcerias e desafios. Rio de Janeiro: EdUerj, 2012. pp. 2944.

36. Global Bioeconomy Consulting LLC. Global Hubs and Global Nodes of Biotecnology: an international scan of biotechnology strategies, initiatives and institutional capacity. 3. ed. Washington: Global Bioeconomy Consulting LLC, 2007. pp. 85-92.

37. Paes MC, Baptista TA. Biotecnologia no Rio de Janeiro: análise de cenário com foco em recursos humanos. Cadernos do Desenvolvimento Fluminense 2014; 4: 184-199.

38. Fonseca MGD, Uziel D. A história e o momento atual da biotecnologia no Brasil. In: Uziel D. (org.). Biotecnologia no Brasil: financiamento, parcerias e desafios. Rio de Janeiro: EdUerj, 2012. pp. 17-28.

39. Rego S, Palacios M, Schramm FR. Ensino da bioética nos cursos de graduação em saúde. In: MARTINS, J. J. N. et al. (Orgs.). Educação médica em transformação. São Paulo: ABEM; Hucitec, 2004

40. Coordenação de Aperfeiçoamento Pessoal de Nível Superior (CAPES). Dados sobre cursos de Biotecnologia. Relação de cursos recomendados pela CAPES, 2015. Disponível em: http://www.capes.gov.br/avaliacao/dados-do-snpg.

41. Buglione S. Direito, Ética e Bioética: Fragmentos do Cotidiano. Rio de Janeiro: Lumen Juris, 2010. 